\title{
Effects of Selective Neonatal Temporal Lobe Lesions on Visual Recognition Memory in Rhesus Monkeys
}

\author{
Jocelyne Bachevalier and Mortimer Mishkin \\ Laboratory of Neuropsychology, National Institute of Mental Health, Bethesda, Maryland
}

\begin{abstract}
Ten-month-old infant monkeys that had received neonatal ablations of either inferior temporal cortex (area TE) or the medial temporal region were compared with age-matched normal infant monkeys in visual delayed nonmatching-tosample with trial-unique objects. Both types of early damage caused impairment in visual recognition, but the degree of deficit after early area TE lesions differed sharply from that after early medial temporal removals. Thus, whereas early medial temporal damage yielded a marked decline in visual recognition when the delays and lists were gradually increased, early area TE damage yielded normal recognition up to a delay of $60 \mathrm{sec}$ and only mild impairment at longer delays and lists. The data indicate that, unlike adult monkeys, which suffer severe and nearly equivalent losses in visual object recognition after both types of ablation, the infant monkeys' recognition ability is largely spared after early damage to area TE but not after early damage to the medial temporal lobe. Together with recent clinical reports of profound memory loss in children with early dysfunction of the medial temporal region, the present findings demonstrate that medial temporal lobe structures operate early to sustain visual recognition memory, and recovery from early damage is limited at best. Early damage to higher-order visual cortex, however, can be largely compensated, presumably by one or more of the visual cortical areas that were left intact.
\end{abstract}

IKey words: memory, medial temporal lobe, inferior temporal cortex, delayed nonmatching-to-sample task, infant monkey]

Bilateral damage to the medial temporal lobe in monkeys results in a profound antcrogradc amnesia, closcly resembling the anterograde amnesia that follows bilateral damage to the medial temporal lobe in humans (Mishkin, 1978, 1982; Mahut et al., 1982; Mishkin et al., 1982; Zola-Morgan and Squire, 1985, 1993; Squire and Zola-Morgan, 1991). In monkeys, as in humans, the memory deficit appears to be global, affecting memory for visual and nonvisual, as well as spatial and nonspatial, stimuli (Murray and Mishkin, 1984; Parkinson et al., 1988). Nev-

\footnotetext{
Received Apr. 16, 1993; revised Sept. 14, 1993; accepted Sept. 29, 1993.

We express our appreciation to Richard C. Saunders for his expert assistance in the MRI scanning of the monkeys. We also thank Howard Crawford, Mimi Brickson, Brad Ruebel, and Jeffrey Youngs for their assistance in the behavioral testing of the infant monkeys and Richard Duntz for supervising the care of the monkeys.

Correspondence should be addressed to Dr. Jocelyne Bachevalier, Department of Neurobiology and Anatomy, University of Texas Medical School, 6431 Fannin Street, Houston, TX 77030.
}

Copyright (C) 1994 Society for Neuroscience $0270-6474 / 94 / 142128-12 \$ 05.00 / 0$ ertheless, despite their severe sensory memory deficits, amnesic monkeys, like amnesic humans, show apparently normal immediate memory as well as preserved habit formation and skill learning abilities, indicating that only selective learning and memory processes are affected by medial temporal damage $(\mathrm{Ma}$ lamut et al., 1984; Zola-Morgan and Squire, 1985, 1993; Overman et al., 1990). The foregoing findings have been obtained in monkeys that had received their lesions in adulthood. As yet, there is little evidence to suggest that the same amnesic syndrome will result from medial temporal damage incurred in early infancy. Case studies in children have yielded potentially contradictory results. For example, no memory impairments were found in clinical cases that have been diagnosed as having bilateral temporal lobe agenesis (Nathan and Smith, 1950; Karvounis et al., 1970; Tuynman et al., 1974; Lang et al., 1981). On the other hand, there are anecdotal reports of severe memory loss in children who developed a Klüver-Bucy syndrome resulting either from hypoxic insults affecting the medial temporal lobe (Tonsgard et al., 1987) or from bitemporal arachnoid cysts (Rossitch and Oakes, 1989). Also, detailed neuropsychological evaluation of a few cases has indicated the presence of childhood anterograde amnesia following either encephalopathy (Ostergaard, 1987), herpes simplex encephalitis (Wood et al. 1989), or medial temporal sclerosis and hippocampal atrophy (VarghaKhadem et al., 1992). In all these amnesic cases, however, the damage was sustained some years after birth, the youngest being 4- and 5-year-old (Vargha-Khadem et al., 1992, and Tonsgard et al., 1987, respectively) all the others being between 9 and 15 years of age.

The present investigation was designed to determine whether neonatal removal of medial temporal lobe structures in monkeys would yield an amnesic syndrome similar to the one described in adult monkeys with equivalent lesions (Mishkin, 1978; Mishkin et al., 1982). In an earlier report we indicated that habit formation ability (as measured by concurrent object discrimination learning with $24 \mathrm{hr}$ intertrial intervals) was spared by early medial temporal lesions (Bachevalier et al., 1990), suggesting that, as in amnesic adult monkeys, at least some learning abilities remain unaffected. In the present study, we assessed whether visual recognition memory [as measurcd by delaycd nonmatching-to-sample (DNMS) with trial-unique objects] would be as severely impaired by neonatal medial temporal lesions as it is by similar lesions performed in adults (Mishkin, 1978; Zola-Morgan and Squire, 1985, 1993).

In adult monkeys, visual recognition memory is critically dependent not only on the medial temporal lobe but also on the inferior temporal area TE (a higher-order visual cortical area connected with medial temporal lobe structures). To determine whether the same corticolimbic complex is essential in infancy, we compared the mnemonic effects of neonatal medial temporal 
damage with those of neonatal area TE lesions. In addition, because early $T E$ damage affects habit formation differently in the two sexes, with greater impairment occurring in females than in males (Bachevalier et al., 1990), we examined whether early TE lesions might also affect recognition memory differently in the two sexes.

Preliminary reports of this work have appeared elsewhere (Bachevalier and Mishkin, 1987; Bachevalier, 1990, 1991).

\section{Materials and Methods}

Subjects. The subjects were 27 rhesus monkeys (Macaca mulatta) aged 10 months at the start of the present study. Eight monkeys (four males and four females) had rcceived bilateral neonatal ablation of cortical area TE (group TE), eight monkeys (four males and four females) had received bilateral neonatal medial temporal removals, including amygdala, hippocampus, periamygdaloid cortex, entorhinal cortex, and a substantial portion of the parahippocampal gyrus (group AH), and 11 monkeys (five males and six females) had remained unoperated controls (group N).

The rearing conditions of the monkeys were detailed in a previous paper (Bachevalier et al., 1990). Briefly, all animals were laboratory born (National Institutes of Health Animal Center, Poolesville, MD) and, at their arrival in the primate nursery of the Laboratory of Neuropsychology (NIMH, Bethesda, MD) the day after their birth, they were assigned to social groups consisting of one normal control and one or two operated animals. The infant monkeys were reared in individual cages that allowed them visual, auditory, and some physical contact. In addition, they were handled several times per day by the experimenters, and the social groups (diads or triads) were placed in a playpen located in the nursery for up to $4 \mathrm{hr}$ daily. These rearing conditions have proven to be optimal for the establishment of normal social relationships in infant primates separated from their mothers at birth (Ruppenthal et al., 1991).

During the first 2 weeks, the newborn monkeys were hand fed a diet of infant Similac formula (SMA with iron) and, at 3 weeks of age, when the infant monkeys were self-feeding, their diet was supplemented with banana pellets $(190 \mathrm{mg}$; P. J. Noyes, Cleveland, OH). At 3 months of age, the milk ration was supplemented with Purina monkey chow and Vidaylin multivitamin plus iron tablets (Ross Lab., Columbus, $\mathrm{OH}$ ), and fresh fruit was given once a week. Throughout training, when banana pellets were used as rewards, the daily milk intake was manipulated to provide each animal with the highest ration consistent with prompt responding in the testing situation. Water was always available.

Behavioral procedure. All the infant monkeys had received behavioral assessment and training prior to the present experiment. This previous testing experience consisted of measurement of their preference to look at novel as compared with familiar objects at the age of 5,15 , and 30 d (Hagger et al., 1985; Bachevalier et al., 1993), their ability to form visual discrimination habits at the age of 3 months (Bachevalier et al., 1990), their social interactions with peers at 2 and 6 months (Merjanian et al., 1986, 1988, 1989), and their reactions toward familiar and novel objects at 9 months (Nalwa and Bachevalier, 1991).

In the present study, the scores of the three groups of infant monkeys were compared with those of three groups of young adult monkeys (approximately 3-4 ycars of agc) reported previously (Mishkin, 1978; Mishkin and Phillips, 1990). These adult groups consisted of three monkeys that had received bilateral $\mathrm{AH}$ ablations (including amygdala, hippocampus, and underlying cortex), three that had received bilateral ablations of area TE, and three unoperated controls.

Surgery. Ablations in the infant monkeys were performed in two stages, the lesion in the left hemisphere when they were approximately 1 week of age, and the lesion in the right hemisphere 12-15 d later, when they were about 3 weeks of age. Surgical procedures, pre- and postoperative care, and postoperative recovery have already been described in detail (Bachevalier et al., 1990). Briefly, all operations were performed aseptically with the aid of a surgical microscope while the animals were under anesthesia induced by a 1:10 mixture of acepromazine-ketamine ( $15 \mathrm{mg} / \mathrm{kg}$, i.m.). Vital signs were monitored throughout surgery, and supplements of anesthetics were administered as required. When the removal was completed, the wounds were sutured in anatomical layers, and the animals were then placed in an incubator until they recovered from anesthesia. They received acetaminophen (Tylenol, $10 \mathrm{mg} / \mathrm{kg}$ orally) for postoperative analgesia, an antibiotic (chloram- phenicol, $12 \mathrm{mg} / \mathrm{kg}$ orally) as a prophylactic measure, and dexamethasone phosphate $(0.5 \mathrm{mg} / \mathrm{kg}$, i.m.) to reduce brain edema.

Removals of inferior temporal cortical area TE extended dorsoventrally from the fundus of the superior temporal sulcus(STS) to the fundus of the occipitotemporal sulcus and the lateral lip of the rhinal sulcus, and they extended rostrocaudally from the anterior tip of STS to a line $9 \mathrm{~mm}$ in front of and parallel to the ascending limb of the inferior occipital sulcus. In adult monkeys, the caudal limit of the lesion is placed $10 \mathrm{~mm}$ rostral and parallel to the inferior occipital sulcus, or approximately one-third of the distance from this sulcus to the rostral tip of STS, yielding a lesion in the adult of approximately the anterior twothirds of the inferior temporal convexity. Because the distance from sulcus to pole is about $10 \%$ less in the infant monkey than in the adult, the line drawn at $9 \mathrm{~mm}$ yields proportionately the same inferior temporal damage in the infant as in the adult. Inasmuch as the caudal limit of the lesion delineates an arbitrary border between areas TE and TEO, a physiologically defined area caudal to TE (Boussaoud et al., 1991), these cytoarchitectonic labels are used here only for convenience.

For the medial temporal removal, the amygdala was first approached through an inferior frontal bone opening, exposing the orbitofrontal cortex, and then elevating it slightly to permit visualization of the medial aspect of the temporal pole. The amygdalar lesion included the entire amygdaloid complex as well as all the underlying cortex (periamygdaloid cortex plus that portion of the entorhinal cortex, area 28, located medial to the rostral half of the rhinal sulcus). The hippocampus was approached through a separate, supralabyrinthine bone opening allowing elevation of the cortex at the occipitotemporal junction. The hippocampal lesion included the hippocampal formation and the underlying cortex (parahippocampal gyrus lying medial to the occipitotemporal sulcus as well as that portion of the entorhinal cortex, area 28 , lying medial to the caudal half of the rhinal sulcus).

Surgical procedures as well as pre-and postsurgical care in the adult monkeys were identical to those described for the infants except for the anesthetic, which was sodium pentobarbital (20-30 mg/kg, i.v.). Also, in the adults, unlike the infants, the bilateral surgical removals were carried out in one stage.

Apparatus. Training on delayed nonmatching-to-sample (DNMS) with trial-unique objects was conducted in a reduced version of the standard Wisconsin General Testing Apparatus (WGTA). The WGTA was located inside a darkened room lined with sound-attenuating tiles. Additional sound masking was provided by a white-noise generator. The test tray, located $6 \mathrm{~cm}$ away from the animal, contained a row of three food wells spaced $10 \mathrm{~cm}$ apart, center to center. A stock of approximately 300 unmounted objects that differed in size, shape, texture, and color were used as stimuli.

DNMS training was started when the animals were 10 months of age, at which time their daily food ration was restricted to compensate for the banana pellet rewards that they gained in the task. Each trial consisted of an acquisition phase, in which a baited sample object was presented over the central well, followed $10 \mathrm{sec}$ later by a test phase. In the test phase, the sample object, now unbaited, was paired with a baited novel object, each of which was presented over a lateral well. Thirty seconds later another set of trials was presented in the same way, but with a new pair of objects, the novel object appearing over the left or right well in a pseudorandom order. Testing continued in this manner at the rate of 20 trials per day, each with a new pair of objects, until the animals reached a criterion of 90 correct responses in 100 consecutive trials or for a maximum of 1500 trials. A noncorrection technique was used throughout.

Following a 2 week rest period, the monkeys were retrained to criterion on DNMS and then given a performance test in which, first, the delay between acquisition and test was increased in stages from the original $10 \mathrm{sec}$ to $30 \mathrm{sec}, 60 \mathrm{sec}$, and finally $120 \mathrm{sec}$, each given for a block of 100 trials distributed over five sessions; and then, the number, or list, of sample objects presented successively in acquisition before pairing each with a novel object in the test phase was increased in stages from the original single object to 3,5 , and finally 10 objects, each presented for a block of 150 trials distributed over five sessions.

Adult monkeys were trained to criterion on the DNMS task prior to surgery. After $15 \mathrm{~d}$ of recovery from surgery, or after a comparable rest period for the unoperated controls, they were retrained to criterion and then given the performance test with increasing delays and lists. Other ways in which their training differed from that for the infants were the use of the standard-sized WGTA and test tray, larger unmounted objects, and peanuts as reward rather than banana pellets. 

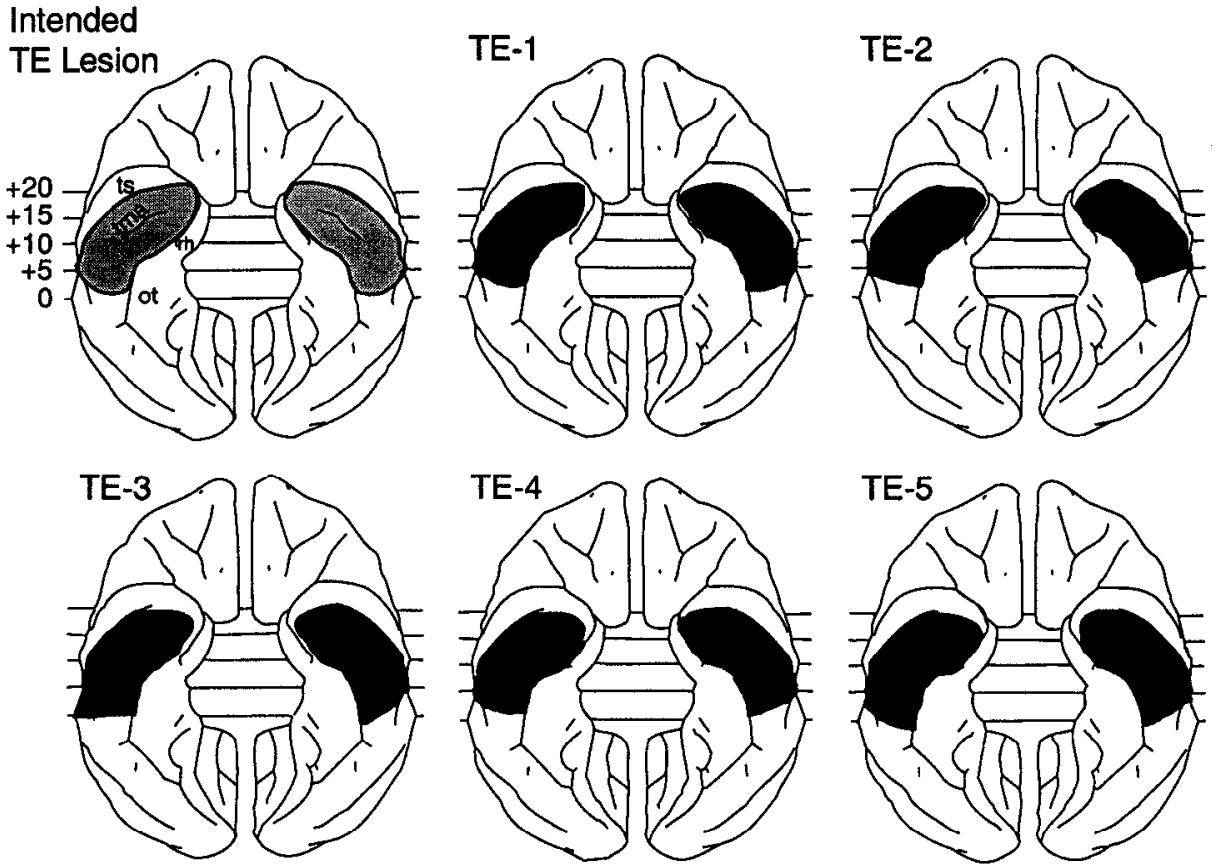

tions of area TE lesions in the eight neonatally operated monkeys (case TE-2 previously reported in Bachevalier et al., 1990). Intended lesion is shown shaded, and actual lesions are in black. Extent of damage in cases TE- I, TE-4, TE-7, and TE-8 was evaluated from MR images. Numerals refer to approximate distance (in $\mathrm{mm}$ ) from the interaural plane. ot, occipitotemporal sulcus; $r h$, rhinal sulcus; $t m a$, anterior middle temporal sulcus; $t m p$, posterior middle temporal sulcus; $t s$, superior temporal sulcus.
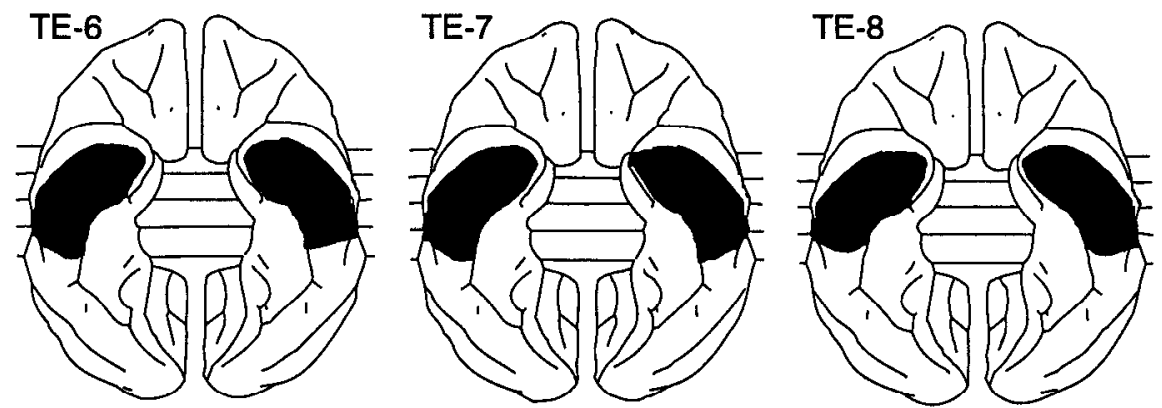

Histology and magnetic resonance images. Although histological data are not yet available for all of the monkeys, the brains of cases TE-2, TE-3, TE-5, TE-6, TE-8, and AH-5 were processed after these monkeys died of bloat at the ages of $1.5,7,7,3.5,7$, and 2 years, respectively. The brains were placed in $10 \%$ formalin and were then cut frozen in the coronal plane at $25 \mu \mathrm{m}$. Every 10th section was stained with thionin and used to reconstruct the lesions. Examination of the brain damage in the remaining monkeys was investigated with magnetic resonance (MR) imaging (Saunders et al., 1990) when they were approximately 7 years of age. MR images (1.5 tesla; GE Signa, Milwaukee, WI) were obtained in the coronal plane using an inversion recovery sequence with an inversion time (TI) of $600 \mathrm{msec}$, a repetition time (TR) of 2500 msec, and an echo time (TE) of $25 \mathrm{msec}$. Field of view (FOV) was 10 $\mathrm{cm}$ with two excitations, and slice thickness was $3 \mathrm{~mm}$ interleaved with offsets of $1 \mathrm{~mm}$, yielding one image every millimeter. The extent of neural damage visible on the MR images was transferred onto the drawings of matched sections from a normal brain, which were then used to reconstruct the lesion onto the ventral surface view of the normal brain. The nearly identical delineations of the lesion from histological sections and from MR images in case TE-8 (the only case for which both types of analysis were available, each performed independently by a different observer), confirmed that aspiration lesions can be estimated precisely from MR images (Saunders et al., 1988).

The TE lesions of all eight cases are shown reconstructed onto standard ventral surface views in Figure 1. Coronal sections through the lesions of two representative cases (TE-3 and TE-5) are illustrated in Figure 2. Removals of cortical area TE were largely as intended. In three of the cases (TE-3, TE-5, and TE-6), a small amount of tissue in the most anterior portion of area TE was spared bilaterally, and in five of the cases (TE-1, TE-3, TE-6, TE-7, and TE-8), the ventromedial border of the lesion spared a strip of tissue about $1 \mathrm{~mm}$ wide lateral to the lateral lip of the rhinal sulcus bilaterally. As for unintended damage, cases TE-3, TE-5, and TE-8 sustained a small amount of unilateral damage to the most anteroventral portion of area TEO.

Histology is available for only one of the eight animals with medial temporal removals (case $\mathrm{AH}-5$ ), and this lesion was illustrated previously (Bachevalier et al., 1990). Examples of the lesions in two cases (AH-3 and AH-4) examined from the MR images, are depicted in Figure 3 , and coronal MR images of one representative case (AH-4) are illustrated in Figure 4. Amount of cortical damage included in the medial temporal removal for the eight cases is shown reconstructed onto standard ventral surface views in Figures 3 and 5. The medial temporal removals were complete bilaterally in all cases, except for sparing of the caudalmost $1-2.5 \mathrm{~mm}$ portion of the hippocampus in four of them (AH-1, AH-5, AH-6, and AH-7). Also in all cases, the lesion included the fundus (as well as the medial bank) of the rhinal sulcus along its entire length, thus encroaching on area 35 of perirhinal cortex. In addition, at the caudal tip of the rhinal sulcus, the lesion included a small amount of damage to perirhinal cortical area 36. Finally, unintended damage was found in the inferior temporal cortex, unilaterally in cases $\mathrm{AH}-1, \mathrm{AH}-2, \mathrm{AH}-3, \mathrm{AH}-6$, and AH-7, and bilaterally in cases AH-4, $\mathrm{AH}-5$, and $\mathrm{AH}-8$, presumably due to a combination of mechanical and ischemic damage. This damage was judged to be potentially significant only in case AH-8, where it averaged $10 \%$ bilaterally of areas TE and TEO combined, and also extended caudally on the ventromedial surface of the left hemisphere to include occipital cortex (see Fig. 5).

\section{Results}

\section{Acquisition and retention of DNMS}

The number of trials and errors each infant monkey required to learn and retain the DNMS principle is given in Table 1, and group means are shown in Figure 6. 
CASE TE-3
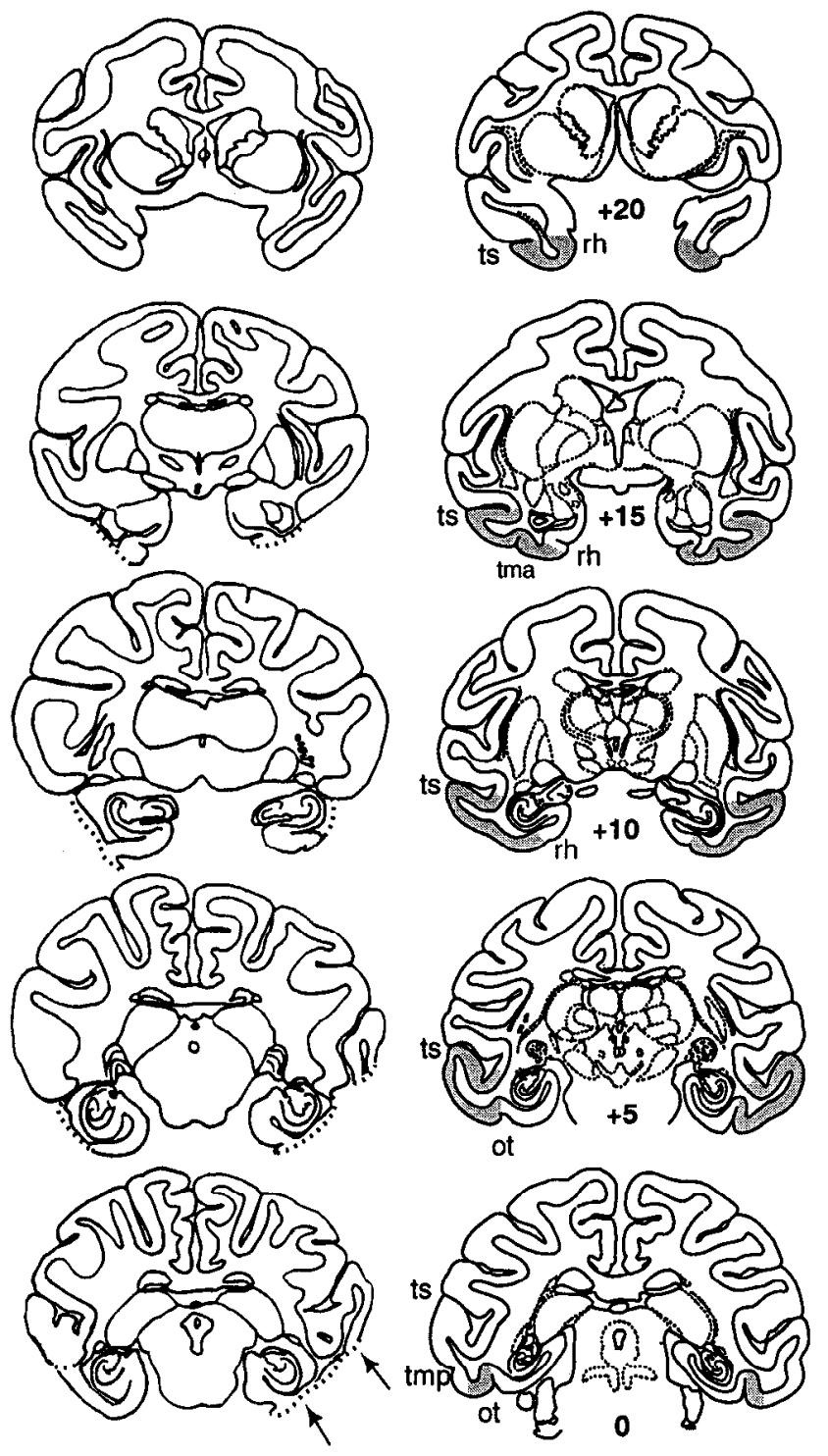
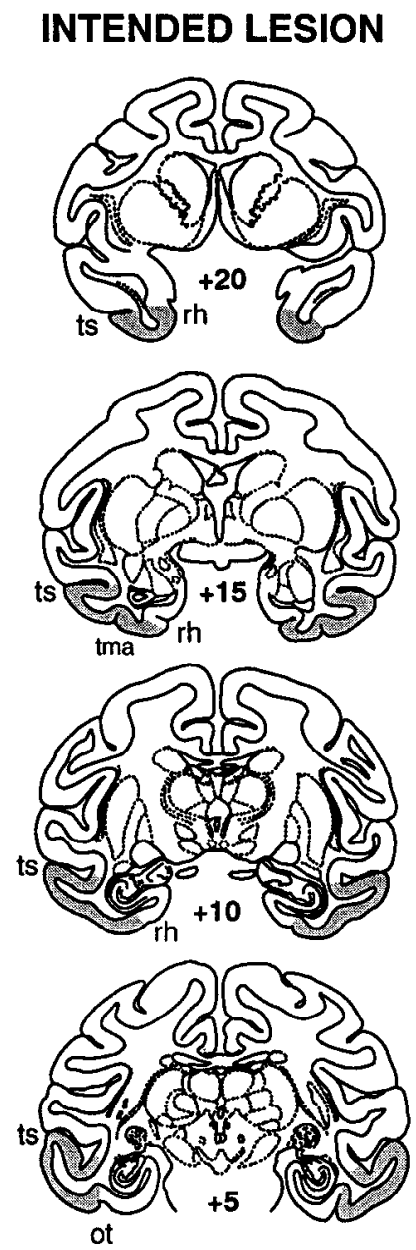

CASE TE-5
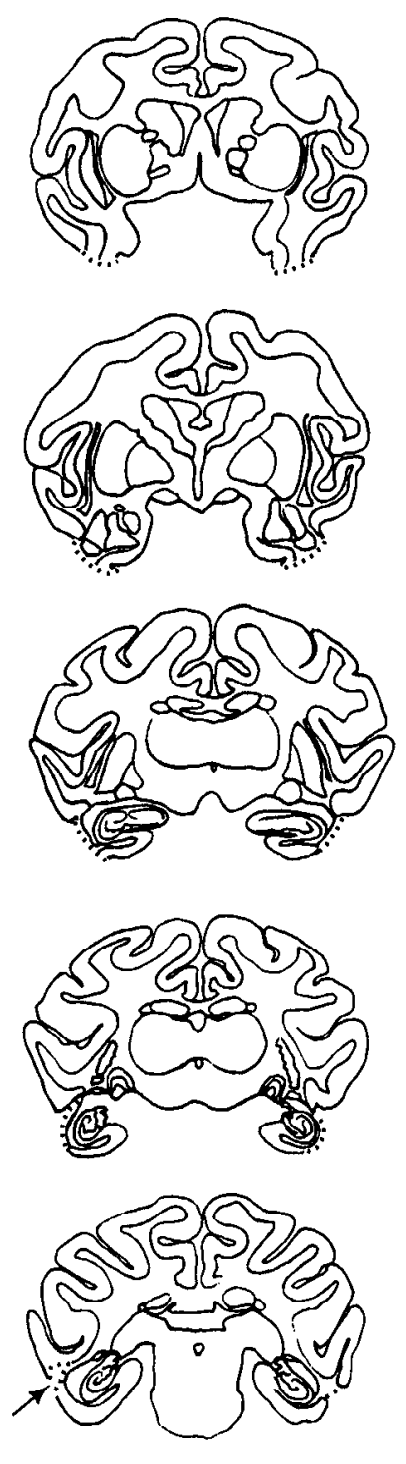

Figure 2. Coronal sections through the inferior temporal lesions in cases TE-3 and TE-5. Intended lesion (middle column) is shown shaded, and actual lesions in the two representative cases are indicated by dotted lines. Arrows (see level 0 ) point to unintended damage to posterior temporal visual area TEO. Numerals and abbreviations are as in Figure 1.
During the acquisition phase, all animals attained criterion within the limit of testing, except case AH-8, which failed after the maximum of 1500 trials. This latter case received additional training with a correction procedure in which an error was followed by (unscored) representations of the test trial until the animal responded correctly. With this correction training, monkey AH-8 reached criterion in an additional 120 trials and 21 errors. Analyses of both trials and errors to learn revealed a significant effect of lesion $(F=4.14, \mathrm{df}=2,21, p<0.05$; and $F=4.75, \mathrm{df}=2,21, p<0.02$, respectively) but not of $\operatorname{sex}(F$ $=0.509$, df $=1,21, \mathrm{NS}$; and $F=0.531$, df $=1,21$, NS, respectively), and no significant interaction. Newman-Keuls paired comparisons indicated that, whereas group TE did not differ reliably from group $\mathrm{N}$, group AH learned more slowly than either ( $p<0.05$ for both trials and errors in each case); the results wcre similar when $\mathrm{AH}-8$, the case with the greatest extralimbic damage, was omitted from the analysis $(p<0.05$ for trials for $\mathrm{AH}$ vs $\mathrm{N}$ only, and $p<0.05$ for errors for both $\mathrm{AH}$ vs $\mathrm{N}$ and $\mathrm{AH}$ vs $\mathrm{TE}$ ).
After the 2 week rest period, all animals showed good retention of the DNMS principle, requiring fewer trials and errors to relearn than they had taken originally. Nonetheless, as compared to the normal controls, which relearned the basic task almost immediately, both operated groups were retarded. Because in all groups some animals relearned the task immediately, resulting in scores of 0 trials and 0 errors, group differences were analyzed by a nonparametric Kruskal-Wallis one-way ANOVA. This analysis indicated a significant effect of groups for both trials $[H(2)=7.20, p<0.03]$ and errors $[H(2)=7.36, p<$ $0.025]$ to criterion. Thus, in retention, unlike acquisition, both groups TE and AH differed significantly from group $\mathrm{N}$ (all $p<$ 0.02 ) and did not differ from each other.

\section{Performance test}

Evidence of a greater deficit from the neonatal medial temporal lesions than from the neonatal inferior temporal cortical lesions is provided by the performance scores shown in Table 2 and Figure 7. A lesion $\times \operatorname{sex} \times$ condition ANOVA, with repeated 


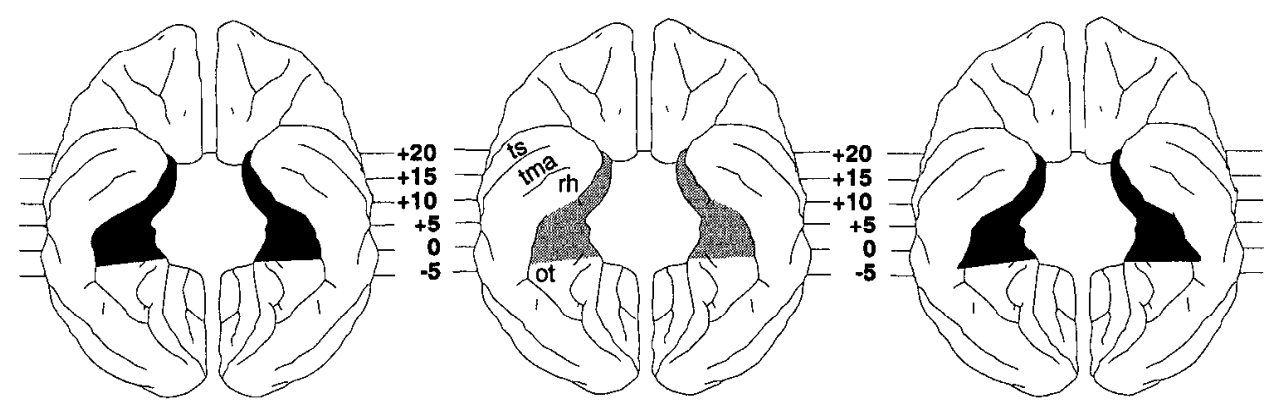

CASE AH-3
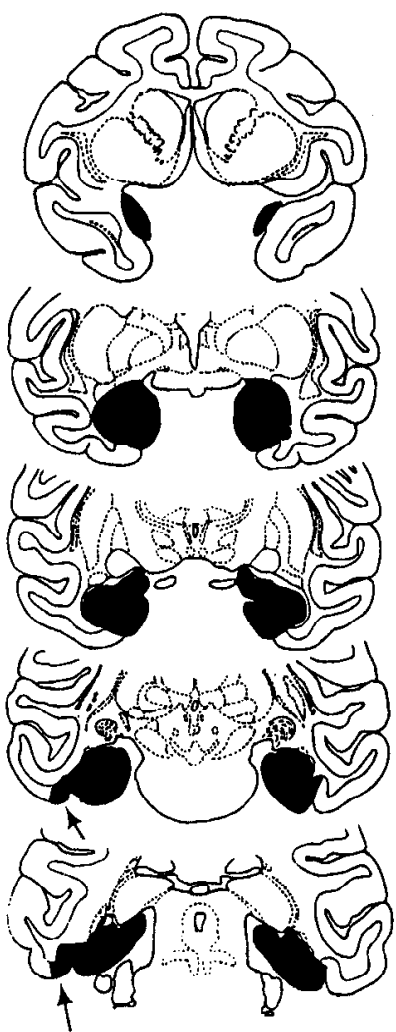

INTENDED LESION
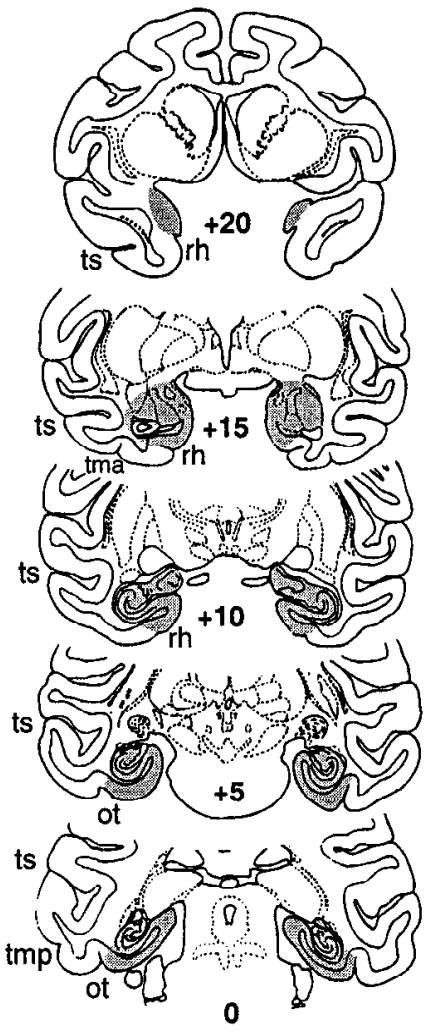

CASE AH-4
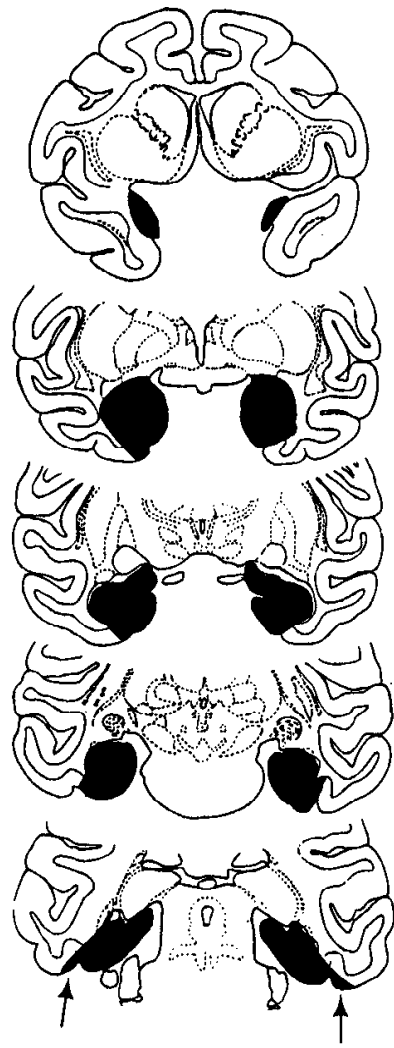

Figure 3. Ventral surface reconstruc-
tions and coronal sections through the lesions in cases $\mathrm{AH}-3$ and $\mathrm{AH}-4$. Intended lesion (middle column) is shown shaded on ventral view of the brain $(t o p)$ and on coronal sections (below), and actual lesions, as measured from MR images transferred onto drawings of matched sections from a normal brain, and reconstructed onto the ventral surface view, are shown in black. Arrows point to slight unintended damage to posterior temporal visual area TEO on the left in case $\mathrm{AH}-3$ (levels +5 and 0 ) and bilaterally in case AH-4 (level 0 ). Numerals and abbreviations are as in Figure 1. measures for the last factor, revealed significant main effects for lesion and condition $[F=52.75$, df $=2,21, p<0.001$; and $F($ conservative $\mathrm{df}=1,21)=82.93, p<0.0005$, respectively] but not for sex. Paired comparisons (Newman-Keuls) indicated that both groups TE and AH performed significantly worse than group $\mathrm{N}$ ( $p<0.05$ in each case) and also that group AH performed significantly worse than group TE $(p<0.05)$. In addition, there was a significant interaction between lesions and condition $[F($ conservative $\mathrm{df}=1,21)=9.95, p<0.005]$ indicating that the scores of one or both operated groups fell disproportionately with increasing memory demands. In fact, this was the case for both groups $\mathrm{AH}$ and $\mathrm{TE}$, since omission of either one from the statistical analysis did not eliminate the significant interaction $[F($ conservative $\mathrm{df}=1,15)=7.89, p<$ 0.025 ; and $F$ (conscrvative $\mathrm{df}=1,15)=21.22, p<0.0001$, after omitting groups $\mathrm{AH}$ and $\mathrm{TE}$, respectively]. Yet the pattern as well as degree of deficit following the two lesions was clearly different. As shown in Table 2 and Figure 7, the mean scores of group TE (91\%) were similar to those of group N (93\%) across the three longer delays, but they were lower $(77 \%)$ than those of group $\mathrm{N}(88 \%)$ across the three longer list lengths. Group $\mathrm{AH}$, by contrast, performed poorly on both measures $(78 \%$ on the delays and $66 \%$ on the list lengths). Separate ANOVAs on the three delays and three list length tests yielded significant effects of lesion on both $[F(2,24)=47.5, p<0.0001$, and $F(2$, $24)=46.2, p<0.0001$, respectively]. In addition, there werc significant effects of delays and lists $[F$ (conservative $\mathrm{df}=1,24)$ $=22.9, p<0.0001$, and $F($ conservative $\mathrm{df}=1,24)=35.8, p$ $<0.0001$, respectively]. Paired comparisons (Newman-Keuls) indicated that, whereas group AH performed significantly more poorly than either of the two other groups on each of the six longer delay and list length conditions ( $p<0.01$ for each), group TE differed from group $\mathrm{N}$ at the longest delay only $(p<0.01)$ and at each list length ( $p<0.01$ for each).

A lesion $\times$ sex ANOVA performed separately for each of the six delay and list length conditions revealed a significant inter- 

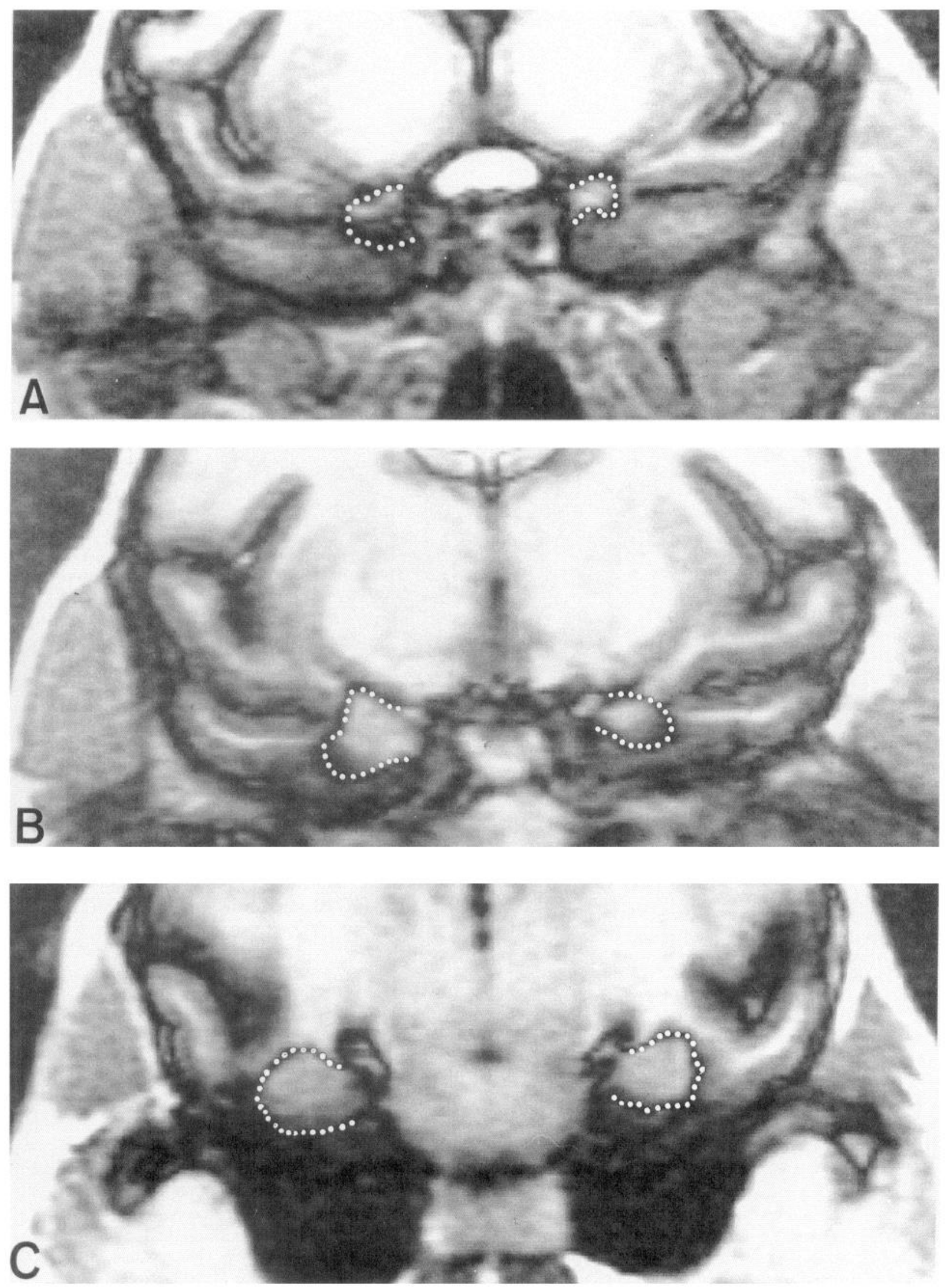

Figure 4. Coronal MR images from case AH-4. $A$, Image through the amygdaloid portion of the lesion at approximately $+15 . B$ and $C$, Images through the hippocampal portion of the lesion, at approximately +10 and +5 , respectively. Dots outline area of lesion. Compare with Figure 3 (right column), where the lesion is delineated on matched coronal sections of a normal brain. The MR images were obtained with an inversion recovery technique: $\mathrm{TI}=600 \mathrm{msec}, \mathrm{TR}=2500 \mathrm{msec}, \mathrm{TE}=25 \mathrm{msec}, \mathrm{FOV}=10 \mathrm{~cm}$ with two excitations, slice thickness $=3 \mathrm{~mm}$ with offsets of $1 \mathrm{~mm}$. 

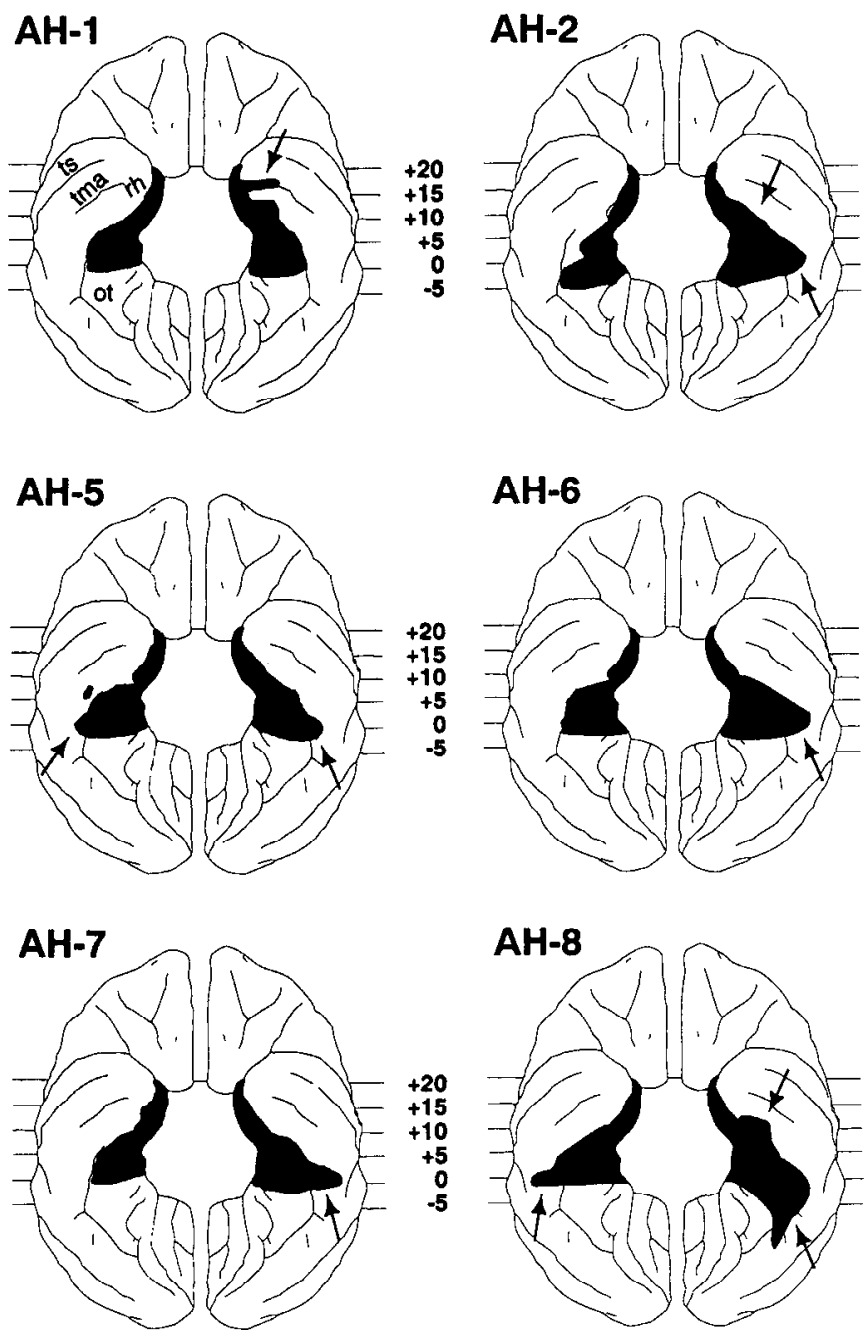

Figure 5. Ventral surface reconstructions of cortical damage (in black) after medial temporal removals in six cases not illustrated in Figure 4 (case AH-5 previously reported in Bachevalier et al., 1990). Arrows point to unintended damage to anterior inferior temporal cortex (area TE and perirhinal area) unilaterally in cases $\mathrm{AH}-1, \mathrm{AH}-2$, and $\mathrm{AH}-8$, and to posterior inferior temporal cortex (area TEO) unilaterally in cases $\mathrm{AH}$ 2 , AH-6, and AH-7 and bilaterally in cases AH-5 and AH-8. Numerals and abbreviations are as in Figure 1.

action between the two factors at the most demanding condition (i.e., list length of 10 objects) $(F=4.57, \mathrm{df}=2,21, p<0.02)$. As indicated by follow-up $t$ tests, the interaction reflected the fact that, in group $\mathrm{AH}$, male infant monkeys performed significantly more poorly on the longest lists than the female infant monkeys $[t(6)=2.54, p=0.04]$.

\section{Early versus late lesions}

The effects of the early inferior temporal and medial temporal lesions were next compared with those of the equivalent lesions performed in adulthood. For this purpose, because only male subjects were used in the study with adult monkeys, the mean score across all six conditions of the performance test was calculated for each male infant and adult (Table 3). The lesion $x$ age ANOVA revealed that both main effects were significant $(F$ $=89.0, \mathrm{df}=2,16, p<0.0001$; and $F=19.79$, df $=1,16, p$ $<0.0001$, respectively), as was their interaction $(F=16.60$, df $=2,16, p<0.0005)$. The interaction reflects the fact that

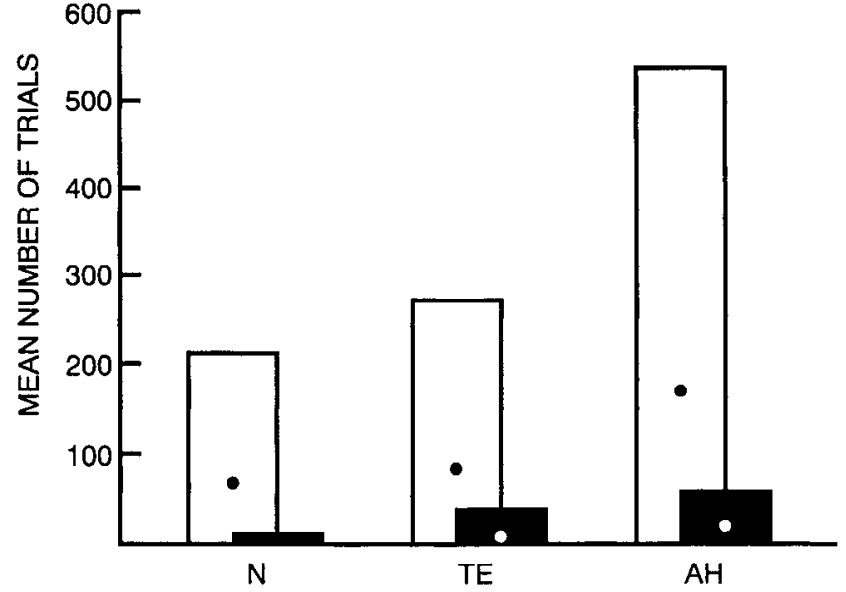

Figure 6. Mean trials to learn (open bars) and relearn (solid bars) DNMS to the criterion of 90 correct responses in 100 trials for normal infant monkeys $(N)$, infant monkeys with area TE lesions $(T E)$, and infant monkeys with medial temporal lesions that included amygdala and hippocampus $(A H)$ plus underlying cortex. Circles indicate mean error scores. A rest period of $15 \mathrm{~d}$ separated the two measurements.

although in adult monkeys both inferior temporal and medial temporal damage caused a large and approximately equal drop in performance from that of the unoperated control group ( $32 \%$ and $37 \%$ decreases, respectively), early damage resulted in drops of only $7 \%$ in the case of the cortical lesions compared with $21 \%$ in the case of the limbic lesions. Although follow-up $t$ tests indicated that the effects of both types of neonatal lesion were significantly less than the effects of both types of adult lesion $[t(5)=5.41, p<0.003$, for the TE lesion, and $t(5)=2.52, p=$ 0.05 , for the AH lesion], these differences were not equivalent. Thus, even when the groups of normal infant and adult monkeys were omitted from the ANOVA, the interaction between lesion and age remained significant $(F=30.06, \mathrm{df}=1,10, p<0.0005)$, indicating that the difference between the effects of adult and neonatal $\mathrm{AH}$ lesions was significantly less than the difference between the effects of the adult and neonatal TE lesions (Fig. 8).

\section{Discussion}

\section{Effects of early medial temporal lesions}

Neonatal removal of the medial temporal region in monkeys yielded a marked deficit in their later visual object recognition ability. The impairment was reflected not only in the difficulty they had both in mastering the DNMS task at 10 months of age and in reattaining criterion after a $15 \mathrm{~d}$ retention interval, but also, and perhaps more significantly, by the sharp decline in their performance when the delays and list lengths were gradually increased. Their disproportionate difficulty with the longer delays and lists strongly suggests that their earlier retardation in learning and relearning the task with $10 \mathrm{sec}$ delays was due not to any difficulty with the nonmatching principle itself (e.g., a reduced preference for novel objects, or a difficulty in adopting the "win-shift" strategy) but rather to a genuine loss in recognition memory. This interpretation is supported by earlier findings in the same monkeys. Thus, they were unimpaired at 3 months of age when tested in a concurrent object discrimination task with $24 \mathrm{hr}$ intertrial intervals (Bachevalier et al., 1990), indicating that they were not deficient in such processes as perception, attention, or motivation, or in performance of instru- 
Table 1. Learning and retention of DNMS

\begin{tabular}{|c|c|c|c|c|c|c|}
\hline \multirow[b]{2}{*}{ Groups } & \multirow[b]{2}{*}{ Subject } & \multicolumn{2}{|c|}{ Learning } & \multicolumn{2}{|c|}{ Retention } & \multirow[b]{2}{*}{ Percentage } \\
\hline & & $\mathrm{T}$ & (E) & $\mathrm{T}$ & (E) & \\
\hline \multicolumn{7}{|l|}{ Group N } \\
\hline \multirow[t]{6}{*}{ Males } & $\mathrm{N}-1$ & 200 & (73) & 0 & $(0)$ & 93 \\
\hline & $\mathrm{N}-5$ & 240 & $(51)$ & 0 & $(0)$ & 91 \\
\hline & $\mathrm{N}-8$ & 160 & (35) & 0 & (0) & 96 \\
\hline & $N-11$ & 180 & (54) & 0 & $(0)$ & 92 \\
\hline & $N-14$ & 180 & (50) & 0 & $(0)$ & 97 \\
\hline & $\bar{X}$ & 192 & (53) & 0 & $(0)$ & 93.8 \\
\hline \multirow[t]{7}{*}{ Females } & $\mathrm{N}-2$ & 120 & (44) & 0 & $(0)$ & 94 \\
\hline & $\mathrm{N}-3$ & 200 & $(88)$ & 0 & $(0)$ & 91 \\
\hline & $\mathrm{N}-6$ & 440 & $(125)$ & 0 & $(0)$ & 95 \\
\hline & $\mathrm{N}-12$ & 200 & $(49)$ & 0 & $(0)$ & 91 \\
\hline & $\mathrm{N}-13$ & 160 & (45) & 60 & $(10)$ & 90 \\
\hline & $N-15$ & 260 & $(110)$ & 0 & $(0)$ & 97 \\
\hline & $\bar{X}$ & 230 & (77) & 10 & (2) & 93.0 \\
\hline \multicolumn{7}{|l|}{ Group TE } \\
\hline \multirow[t]{5}{*}{ Males } & TE-2 & 200 & (43) & 40 & (7) & 90 \\
\hline & TE-4 & 480 & $(157)$ & 60 & $(18)$ & 94 \\
\hline & TE-6 & 160 & $(51)$ & 0 & (0) & 94 \\
\hline & TE-7 & 360 & $(124)$ & 20 & (4) & 91 \\
\hline & $\bar{X}$ & 300 & (94) & 30 & (7) & 92.3 \\
\hline \multirow[t]{5}{*}{ Females } & TE-1 & 320 & $(117)$ & 60 & (9) & 91 \\
\hline & TE-3 & 220 & $(67)$ & 0 & $(0)$ & 93 \\
\hline & TE-5 & 220 & $(78)$ & 100 & $(23)$ & 91 \\
\hline & TE-8 & 200 & (69) & 0 & (0) & 98 \\
\hline & $\bar{X}$ & 240 & (83) & 40 & (8) & 93.3 \\
\hline \multicolumn{7}{|l|}{ Group AH } \\
\hline \multirow[t]{5}{*}{ Males } & $\mathrm{AH}-2$ & 360 & $(154)$ & 140 & $(31)$ & 90 \\
\hline & AH-4 & 240 & $(82)$ & 40 & (5) & 90 \\
\hline & AH-7 & 400 & $(125)$ & 60 & (25) & 90 \\
\hline & $\mathrm{AH}-8$ & $1500 \mathrm{~F}$ & $(457)$ & 0 & (0) & 90 \\
\hline & $\bar{X}$ & 625 & (205) & 60 & (15) & 90 \\
\hline \multirow[t]{5}{*}{ Females } & AH-1 & 480 & $(159)$ & 100 & (15) & 91 \\
\hline & AH-3 & 500 & $(143)$ & 100 & (34) & 90 \\
\hline & AH-5 & 160 & $(66)$ & 0 & $(0)$ & 91 \\
\hline & AH-6 & 620 & $(149)$ & 0 & $(0)$ & 90 \\
\hline & $\bar{X}$ & 440 & $(129)$ & 50 & (12) & 90.5 \\
\hline
\end{tabular}

Scores are numbers of trials, $T$, and errors (E), preceding criterion, and percentage correct choices in the last 100 (criterion) trials. Group N, normal controls; group TE, animals with bilateral area TE lesions; and group AH, animals with bilateral medial temporal lesions, including amygdala, hippocampus, and underlying cortex.

mental choice responses. Conversely, still earlier in their experimental history, they had shown marked impairment in a paired-comparison, preferential looking task which measures, among others, memory for objects viewed just $10 \mathrm{sec}$ earlier (Bachevalier et al., 1993); because this task did not require the instrumental learning of a nonmatching principle, the results provide particularly strong evidence that their impairment on DNMS, even in initial learning at the $10 \mathrm{sec}$ delay, was due to a genuine memory loss.

Impairment in visual recognition memory in infant monkeys has been reported to follow lesions of the hippocampal formation alone, performed when the animals were approximately 2 months of age (Rehbein et al., 1980; Mahut and Moss, 1984, 1986; Mahut and Killiany, 1990). In all eight cases, however, the lesions are described as having encroached on inferior temporal cortical areas TE and TEO, and, in all cases but two, on ento- and perirhinal cortical areas (see Mahut and Moss, 1986 , pp 250-251). Our own results from a recent investigation (Bachevalier and Mishkin, 1991) indicate that damage to these cortical areas, rather than to the hippocampal formation, may well have been responsible for the deficit in recognition memory found in studies by Mahut et al. That is, monkeys given neonatal hippocampal lesions that included much of the parahippocampal gyrus but did not encroach on adjacent inferior temporal or perirhinal areas were found to have a visual recognition ability equal to that of normal controls. The difference in the outcome of these hippocampal lesion studies could be due either to the difference in the age at which the lesions were performed (2 months vs less than 1 month) or, more likely, to the presence versus absence of damage to inferior temporal or perirhinal cortical areas. The latter suggestion is consistent with the mounting evidence from studies in adult monkeys that the medial 


\begin{tabular}{|c|c|c|c|c|c|c|c|c|}
\hline \multirow[b]{2}{*}{ Groups } & \multirow[b]{2}{*}{ Subject } & \multicolumn{3}{|c|}{ Delays (sec) } & \multicolumn{3}{|c|}{ List lengths } & \multirow[b]{2}{*}{$\mathrm{AVG}$} \\
\hline & & $\overline{30}$ & 60 & 120 & 3 & 5 & 10 & \\
\hline \multicolumn{9}{|l|}{ Group N } \\
\hline \multirow[t]{6}{*}{ Males } & $\mathrm{N}-1$ & 94 & 93 & 91 & 94 & 91 & 73 & 89.3 \\
\hline & $\mathrm{N}-5$ & 89 & 92 & 87 & 92 & 90 & 80 & 88.3 \\
\hline & $\mathrm{N}-8$ & 94 & 98 & 91 & 94 & 94 & 86 & 92.8 \\
\hline & $\mathrm{N}-11$ & 97 & 93 & 93 & 93 & 89 & 80 & 90.8 \\
\hline & N-14 & 92 & 95 & 97 & 97 & 93 & 89 & 93.8 \\
\hline & $\bar{X}$ & 93 & 94 & 92 & 94 & 91 & 82 & 91.0 \\
\hline \multirow[t]{7}{*}{ Females } & $\mathrm{N}-2$ & 97 & 94 & 95 & 92 & 87 & 89 & 92.3 \\
\hline & $\mathrm{N}-3$ & 89 & 90 & 94 & 87 & 90 & 84 & $89.0^{\circ}$ \\
\hline & $\mathrm{N}-6$ & 94 & 95 & 84 & 90 & 89 & 77 & 88.2 \\
\hline & $\mathrm{N}-12$ & 92 & 91 & 94 & 91 & 91 & 91 & 91.6 \\
\hline & $\mathrm{N}-13$ & 93 & 92 & 91 & 92 & 84 & 81 & 88.8 \\
\hline & $\mathrm{N}-15$ & 98 & 98 & 93 & 96 & 83 & 77 & 90.8 \\
\hline & $\bar{X}$ & 94 & 93 & 92 & 91 & 87 & 83 & 90.1 \\
\hline \multicolumn{9}{|l|}{ Group TE } \\
\hline \multirow[t]{5}{*}{ Males } & TE-2 & 95 & 94 & 92 & 90 & 89 & 79 & 89.8 \\
\hline & TE-4 & 93 & 92 & 81 & 70 & 63 & 71 & 78.3 \\
\hline & TE-6 & 92 & 93 & 79 & 79 & 65 & 69 & 79.5 \\
\hline & TE-7 & 89 & 96 & 87 & 83 & 89 & 85 & 88.1 \\
\hline & $\bar{X}$ & 92 & 94 & 85 & 81 & 77 & 76 & 83.9 \\
\hline \multirow[t]{5}{*}{ Females } & TE-1 & 92 & 90 & 82 & 76 & 67 & 58 & 77.5 \\
\hline & TE-3 & 94 & 93 & 86 & 85 & 75 & 63 & 82.6 \\
\hline & TE-5 & 90 & 93 & 84 & 88 & 75 & 70 & 83.3 \\
\hline & TE-8 & 95 & 94 & 96 & 91 & 91 & 77 & 90.6 \\
\hline & $\bar{X}$ & 93 & 93 & 87 & 85 & 77 & 67 & 83.5 \\
\hline \multicolumn{9}{|l|}{ Group AH } \\
\hline \multirow[t]{5}{*}{ Males } & $\mathrm{AH}-2$ & 79 & 64 & 72 & 73 & 52 & 53 & 65.5 \\
\hline & $\mathrm{AH}-4$ & 82 & 76 & 64 & 75 & 62 & 59 & 69.6 \\
\hline & $\mathrm{AH}-7$ & 83 & 74 & 65 & 75 & 60 & 55 & 68.6 \\
\hline & AH- 8 & 85 & 93 & 74 & 73 & 69 & 64 & 76.3 \\
\hline & $\bar{X}$ & 82 & 77 & 69 & 74 & 61 & 58 & 70.0 \\
\hline \multirow[t]{5}{*}{ Females } & $\mathrm{AH}-1$ & 90 & 85 & 78 & 74 & 58 & 67 & 75.3 \\
\hline & $\mathrm{AH}-3$ & 80 & 77 & 76 & 66 & 61 & 68 & 71.3 \\
\hline & AH-5 & 90 & 83 & 80 & 76 & 70 & 67 & 77.6 \\
\hline & AH-6 & 91 & 70 & 69 & 69 & 65 & 60 & 70.6 \\
\hline & $\bar{X}$ & 88 & 79 & 76 & 71 & 64 & 66 & 73.7 \\
\hline
\end{tabular}

Scores are percentage correct responses in 100 trials at each delay interval and 150 trials at each list length. AVG denotes average score across the six conditions of the performance test. Conventions are as in Table 1.

temporal tissue most critical for recognition memory is the cortex located in and around the rhinal sulcus (for reviews of this literature, see Murray, 1992; Meunier et al., 1993).

Although neonatal medial temporal lesions yielded substantial impairment in visual object recognition, there was nevertheless a marked reduction in the magnitude of their effects compared to the effects of the same lesions in adults (Mishkin, 1978). Whereas late lesions resulted in an average drop in scores on the performance test of $37 \%$ from the level of the normal controls, early lesions resulted in a drop of only $23 \%$. One possible explanation for the greater impairment in the adult monkeys is that they sustained a greater amount of unintended damage to cortical areas known to participate in visual recognition memory in the adult, such as inferior temporal cortical areas TE and TEO (Mishkin and Phillips, 1990), and the perirhinal cortical area 36 (Murray and Mishkin, 1986; Horel et al., 1987; Murray et al., 1989; Zola-Morgan et al., 1989b; Murray, 1992;
Meunier et al., 1993). A reexamination (Mishkin and Phillips, 1990) of the lesions in the three adult monkeys of the earlier study (Mishkin, 1978) indicates that, in each case, additional unintended cortical damage was in fact present; specifically, in two cases, the lesion encroached on the posterior half of perirhinal area 36 unilaterally and on the ventral portion of areas TE and TEO bilaterally, and in the third case (AH-2) all these areas sustained bilateral infarction. Although a contribution from this extra damage thus cannot be ruled out, it is unlikely to account for the entire difference between the early and late lesion groups, since the extent of the extra damage was relatively minor in the first two cases cited above, amounting to less than $20 \%$ bilaterally of perirhinal cortex and less than $10 \%$ bilaterally of the modality-specific inferior temporal cortex.

Another possibility that must be considered is that the milder behavioral deficit in the monkeys with neonatal lesions resulted from the separation of their surgery into two stages, a procedure 


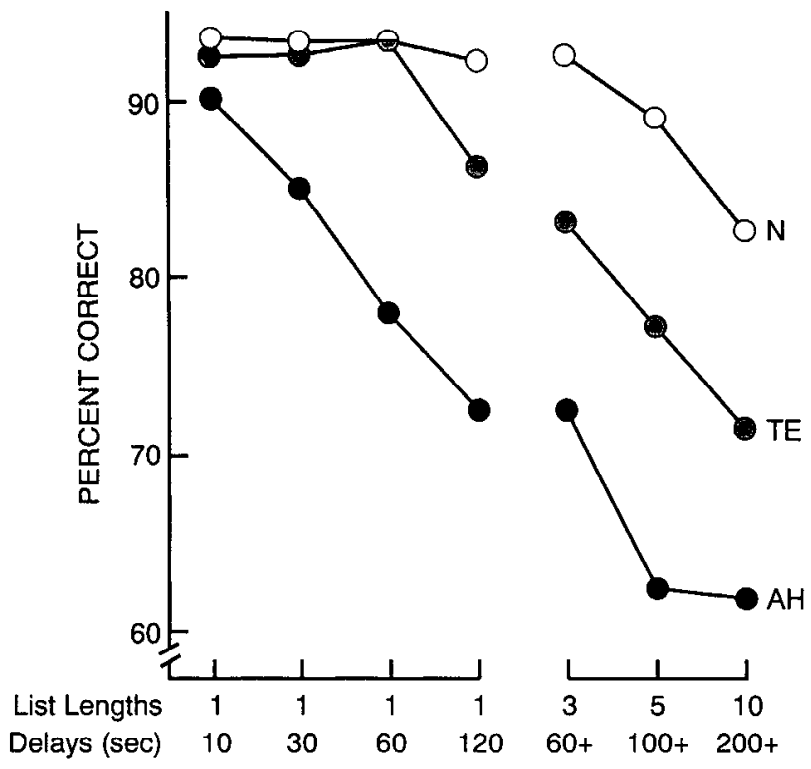

Figure 7. Mean scores on the recognition performance test by normal infant monkeys $(N)$, infant monkeys with area TE lesions $(T E)$, and infant monkeys with medial temporal lesions that included the amygdala and hippocampus $(A H)$ plus underlying cortex. The first point of the curve indicates the average final score achieved during the relearning of the basic task, which entailed recognizing a single object after $10 \mathrm{sec}$. Animals were tested on the six remaining conditions, involving gradually increasing delays and list lengths, for 1 week each.

known to reduce behavioral deficits in adults (Stein et al., 1969; Greene et al., 1972; Dawson et al., 1973; Butters et al., 1974; Corwin et al., 1982). Unlike the case in the adult animals, however, here the interval between the two surgical stages was short (12-15 d as compared to 30-84 d). Also, there was no interoperative training, a procedure known to provide the major benefits of two-stage operations in adults (Greene et al., 1972; Dawson et al., 1973; Corwin et al., 1982). Nevertheless, to examine the issue directly, one infant monkey was given a one-stage bilateral area TE lesion at 1 week of age but was otherwise treated in the same way as the infant monkeys of the present study (M. Webster and J. Bachevalier, unpublished observations). This animal required 220 trials to learn the DNMS task and scored $86.2 \%$ across the six conditions of the performance test as compared to an average of 270 trials and $83.7 \%$ for the eight cases in the present study. Since the two-stage lesions of area TE in infant monkeys yielded even greater sparing of visual recognition than the two-stage $\mathrm{AH}$ lesions, the finding in this case makes it extremely unlikely that the different behavioral outcomes in the infant and adult monkeys after either type of lesion is attributable to the difference in surgical procedure.

Comparison of the scores on the performance test of the normal monkeys in the infant and adult groups raises still another possible explanation of the age $\times$ lesion interaction. As shown in Table 3, none of the normal 10-month-olds reached the level of performance attained by the three normal adults in either the delay or list length conditions. Perhaps with further maturation the normal infant monkeys, but not those with lesions, would improve their performance and thereby reveal a more severe impairment in the operated groups. This possibility has been ruled out, however: retest data obtained when some of these animals were 4 years of age indicate that the levels of performance of the operated and normal control groups, and hence

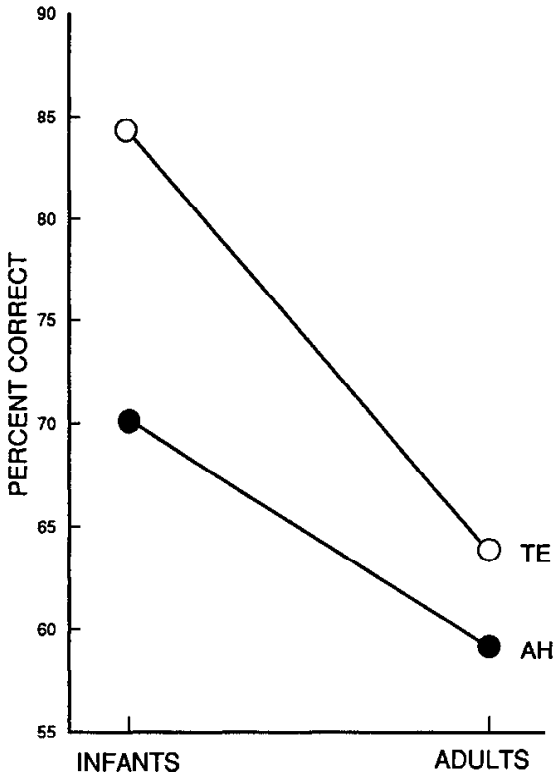

Figure 8. Mean scores across all six conditions of the recognition performance test (three longer delays and list lengths) for male infant and adult monkeys with neonatal medial temporal $(A H)$ and inferior temporal $(T E)$ lesions.

the magnitude of the memory impairment after neonatal temporal lobe lesions, remained the same in adulthood as in infancy (Bachevalier and Mishkin, 1988).

The final possibility to be considered is that experiential factors during the first postsurgical year led to partial compensation by intact neural structures for the functions normally served by the damaged structures (Goldman, 1976). Although experiential factors operating for the same length of time do not seem to improve the performance of monkeys with adult lesions (ZolaMorgan et al., 1989a), experience during the period of development could have far more beneficial consequences. This presently appears to be the most likely explanation for the superior performance of the infant as compared with the adult monkeys with medial temporal lesions, and fits the accumulating evidence referred to earlier that the tissue critical for recognition memory may be neither the amygdala nor the hippocampus, which were essentially totally removed in both groups, but rhinal cortical tissue, which was damaged only partially in both. Thus, the partially spared rhinal tissue may well have provided the sub-

Table 3. DNMS performance test

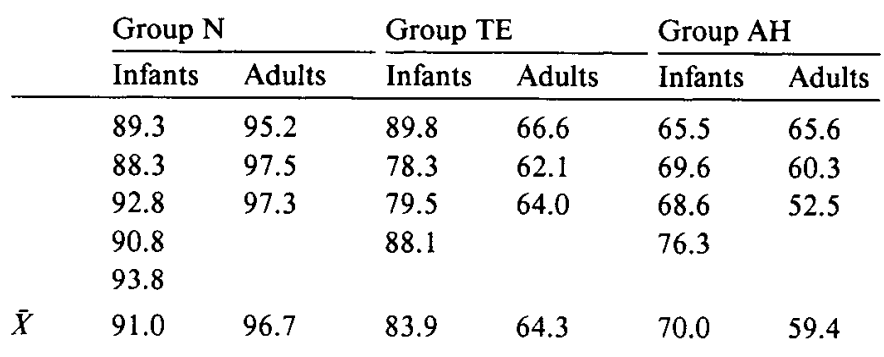

Scores are average percentage correct responses for the six conditions (three delays and three lists) for each male infant and adult monkey. Group $N$, normal controls; group TE, animals with bilateral area TE lesions; group $\mathrm{AH}$, animals with bilateral medial temporal lesions, including amygdala, hippocampus, and underlying cortex. 
strate for the degree of behavioral sparing that the infant $\mathrm{AH}$ group exhibited. At the same time, it is clear that neonatal medial temporal removals still yield substantial visual recognition loss, demonstrating that medial temporal lobe structures operate early in life to sustain visual recognition memory, and that recovery from early damage is rather limited.

These results in infant monkeys are consistent with the clinical observation that children who sustain medial temporal lobe damage even at the age of 4 or 5 years will develop significant anterograde amnesia (Tonsgard et al., 1987; Vargha-Khadem et al., 1992) and suggest further that the same result might well ensue no matter how early postnatally such damage occurs. Whether the same applics to the cffects of prenatal damage, however, is unclear. The apparent absence of memory disorders in children with agenesis of the temporal lobe (Nathan and Smith, 1950; Karvounis et al., 1970; Tuynman et al., 1974; Lang et al., 1981) suggests that there could well be a critical period in fetal development prior to which medial temporal damage may still be fully compensated.

\section{Effects of early area TE lesions}

In contrast to monkeys given area TE lesions in adulthood, which exhibit severe impairment in visual recognition memory (Mishkin, 1982; Mishkin and Phillips, 1990), the neonatally operated monkeys showed substantial sparing of the ability when it was measured at 10 months of age. This was reflected in their nearly normal learning of the DNMS task, their minimal impairment in retention, and their normal-level scores on the performance test through delay intervals of $60 \mathrm{sec}$. Only at the 120 sec delay interval and on the list-length tests did the TE group show significant impairment, and even then the difference between their scores and those of the normal controls averaged less than $10 \%$. This pattern of results corroborates the essentially normal recognition ability with short delays found soon after surgery in the same animals when they were tested in the pairedcomparison preferential-looking task (Hagger et al., 1985) referred to earlier. The degree of impairment after neonatal area TE lesions thus differs sharply from that after neonatal medial temporal removals. In adults, on the other hand, these two types of ablation produce severe and nearly equivalent losses in visual object recognition, whether this is measured by the preferentiallooking or the DNMS task (Mishkin, 1978; Hagger et al., 1985; Mishkin and Phillips, 1990; Bachevalier et al., 1993). These findings demonstrate that area TE is not critical to visual recognition in early infancy, a conclusion supported by recent metabolic (Bachevalier et al., 1991) and electrophysiological (Rodman et al., 1991) studies in infant primates, indicating that area TE is still functionally immature until at least 3 months of age. During this period, in the absence of area TE, other visual areas can apparently assume much of area TE's visual memory functions. Indeed, recent anatomical studies suggest that such compensation could be provided by area TEO as well as other stations in the occipitotemporal visual pathway. The anatomical findings indicate that, neonatally, area TEO sends direct projections to the medial temporal region, specifically to the amygdala and parahippocampal area TF. Normally, these projections regress during development, but after early damage to area TE the normally transient projections are permanently retained (Webster et al., 1990, 1991). Perhaps as a result of such neural reorganization following early damage to area TE, a lesion that in the adult effectively disconnects the medial temporal region from visual input does not do so in the infant.
Yet the early damage to area TE did produce significant impairment, particularly on the list-length tests. Interestingly, this pattern of deficit closely resembles the pattern observed after late damage to area TEO, where it has been attributed to a disorder in the perception of shape, a dimension that is likely to be particularly important for remembering multiple objects in a list as compared to a single object, where color or size alone might do (Mishkin, 1982; Mishkin and Phillips, 1990). If this interpretation is correct, and if the function of area TE in the neonatally operated monkeys has been assumed at least in part by area TEO, then this functional reorganization may have occurred at the cost of the shape perception functions of area TEO (Iwai and Mishkin, 1968; Iwai, 1985), resulting in the pattern of deficit found here.

In the study on visual habit formation (Bachevalier et al., 1990), begun when these animals were 3 months old, the female monkeys with neonatal TE lesions had shown significantly greater impairment than the male monkeys. No such difference was evident in the present study on visual recognition memory. (Indeed, no sex differences were seen in the present study, with the exception of the greater impairment in the male than in the female AH group on the longest list length.) Whether the difference in results is to be accounted for by the difference in the learning abilities measured in the two studies (habit formation vs recognition memory) or in the age at which the measurements were made ( 3 months vs 10 months) remains to be determined.

\section{References}

Bachevalier J (1990) Ontogenetic development of habit and memory formation in primates. Ann NY Acad Sci 608:457-484.

Bachevalier J (1991) Memory loss and socio-emotional disturbances following neonatal limbic lesions in monkeys: an animal model for childhood autism. In: Advances in neuropsychiatry: schizophrenia (Tamminga CA, Schulz. SC, eds), pp 129-140. New York: Raven.

Bachevalier J, Mishkin M (1987) Visual recognition in infant rhesus monkeys: effects of neocortical vs. limbic lesions. Neuroscience [Suppl] 22:S134.

Bachevalier J, Mishkin M (1988) Long-term effects of neonatal temporal cortical and limbic lesions on habit and memory formation in rhesus monkeys. Soc Neurosci Abstr 14:1.

Bachevalier J, Mishkin M (1991) Effects of neonatal lesions of the amygdaloid complex or hippocampal formation on the development of visual recognition memory. Soc Neurosci Abstr 17: 338.

Bachevalier J, Brickson M, Hagger C, Mishkin M (1990) Age and sex differences in the effects of selective temporal lobe lesion on the formation of visual discrimination habits in rhesus monkeys. Behav Neurosci 104:885-899.

Bachevalier J, Hagger C, Mishkin M (1991) Functional maturation of the occipitotemporal pathway in infant rhesus monkeys. In: Alfred Benzon Symposium 31, Brain work and mental activity, quantitative studies with radioactive tracers (Lassen NA, Ingvar DH, Raichle ME, Friberg L, eds), pp 231-241. Copenhagen: Munksgaard.

Bachevalier J, Brickson M, Hagger C (1993) Limbic-dependent recognition memory in monkeys develops early in infancy. Neuroreport 4:77-80.

Boussaoud D, Desimone R, Ungerleider LG (1991) Visual topography of area TEO in the macaque. J Comp Neurol 306:554-575.

Butters N, Rosen J, Stein D (1974) Recovery of behavioral functions after sequential ablation of the frontal lobes of monkeys. In: Plasticity and recovery of function in the central nervous system (Stein DG, Rosen JJ, Butters N, eds), pp 429-466. New York: Academic.

Corwin JV, Vicedomini JP, Nonneman AJ, Valentino I. (1982) Serial lesion effect in rat medial frontal cortex as a function of age. Neurobiol Aging 3:69-76.

Dawson RG, Conrad L, Lynch G (1973) Single and two-stage hippocampal lesions: a similar syndrome. Exp Neurol 40:263-277.

Goldman PM (1976) The role of experience in recovery of function following prefrontal lesions in infant monkeys. Neuropsychologia 14: $401-412$. 
Greene E, Stauff C, Walters J (1972) Recovery of function with twostage lesions of fornix. Exp Neurol 37:14-22.

Hagger C, Brickson M, Bachevalier J (1985) Sparing of visual recognition after neonatal lesions of inferior temporal cortex in infant rhesus monkeys. Soc Neurosci Abstr 11:831.

Horel JA, Pytko-Joiner DE, Voytko ML, Salsbury K (1987) The performance of visual tasks while segments of the inferior temporal cortex are suppressed by cold. Behav Brain Res 23:29-42.

Iwai E (1985) Neuropsychological basis of pattern vision in macaque monkeys. Vision Res 25:425-439.

Iwai E, Mishkin M (1968) Two visual foci in the temporal lobe of monkeys. In: Neurophysiological basis of learning and memory (Yoshii N, Buckwald NA, eds), pp 1-11. Osaka: Osaka UP.

Karvounis PC, Chiu JC, Parsa K, Gilbert S (1970) Agenesis of temporal lobe and arachnoid cyst. NY State J Med 2349-2353.

Lang C, Lehrl S, Huk W (1981) A case of bilateral temporal lobe agenesis. J Neurol Neurosurg Psychiatry 44:626-630.

Mahut H, Killiany R (1990) Ontogeny of object-reward association learning and trial-unique object recognition memory-effects of early hippocampectomy on the two capacities in rhesus macaques. Soc Neurosci Abstr 16:847.

Mahut H, Moss M (1984) Consolidation of memory: the hippocampus revisited. In: Neuropsychology of memory (Squire LR, Butters N, eds), pp 297-315. New York: Guilford.

Mahut H, Moss M (1986) The monkey and the sea horse. In: The hippocampus, Vol 4 (Isaacson RL, Pribram KL, eds), pp 241-279. New York: Plenum.

Mahut H, Zola-Morgan S, Moss M (1982) Hippocampal resections impair associative learning and recognition memory in the monkey. J Neurosci 2:ł214-1229.

Malamut BL, Saunders RC, Mishkin M (1984) Monkeys with combined amygdalo-hippocampal lesions succeed in object discrimination learning despite 24-hour intertrial intervals. Behav Neurosci 98 : 759-769.

Merjanian PM, Bachevalier J, Crawford H, Mishkin M (1986) Socioemotional disturbances in the developing rhesus monkey following neonatal limbic lesions. Soc Neurosci Abstr 12:23.

Merjanian PM, Bachevalier J, Pettigrew KD, Mishkin M (1988) Developmental time course as well as nature of socio-emotional disturbances in rhesus monkey following neonatal limbic lesions resemble those in autism. Soc Neurosci Abstr 14:2.

Merjanian PM, Bachevalier J, Pettigrew KD, Mishkin M (1989) Behavioral disturbances in the developing rhesus monkeys following neonatal lesions of inferior temporal cortex (area TE) resemble those in attention-deficit hyperactivity disorder. Soc Neurosci Abstr 15: 302.

Meunier M, Bachevalier J, Mishkin M, Murray EA (1993) Effects on visual recognition of combined and separate ablations of entorhinal and perirhinal cortex in rhesus monkeys. J Neurosci 13:5419-5433.

Mishkin M (1978) Memory in monkeys severely impaired by combined but not by separate removal of amygdala and hippocampus. Nature 273:297-298

Mishkin M (1982) A memory system in the monkey. Philos Trans R Soc Lond [Biol] 298:85-95.

Mishkin M, Phillips RR (1990) A corticolimbic memory path revealed through its disconnection. In: Brain circuits and functions of the mind. Essays in honor of Roger W. Sperry (Trevarthen C, ed), pp 196-210. Cambridge: Cambridge UP.

Mishkin M, Spiegler BJ, Saunders RC, Malamut BL (1982) An animal model of global amnesia. In: Alzheimer's disease: a report of progress (Corkin S, Davis KL, Growdon JH, Usdin E, Wurtman RJ, eds), pp 235-247. New York: Raven.

Murray EA (1992) Medial temporal lobe structures contributing to recognition memory: the amygdaloid complex versus the rhinal cortex. In: The amygdala: neurobiological aspects of emotion, memory, and mental dysfunction (Aggleton JP, ed), pp 453-470. New York: Wiley-Liss.

Murray EA, Mishkin M (1984) Severe tactual as well as visual memory deficits follow combined removal of the amygdala and hippocampus in monkeys. Brain Res 270:340-344.

Murray EA, Mishkin M (1986) Visual recognition in monkeys following rhinal cortical ablations combined with either amygdalectomy or hippocampectomy. J Neurosci 6:1991-2003.
Murray EA, Bachevalier J, Mishkin M (1989) Effects of rhinal cortical lesions on visual recognition memory in rhesus monkeys. Soc Neurosci Abstr 15:342.

Nalwa V, Bachevalier J (1991) Absence of Klüver-Bucy symptoms after neonatal limbic lesions in infant rhesus monkeys. Soc Neurosci Abstr 17:664.

Nathan PW, Smith MC (1950) Normal mentality associated with a maldeveloped rhinencephalon. J Neurol Neurosurg Psychiatry 13: 191-197.

Ostergaard AL (1987) Episodic, semantic and procedural memory in a case of amnesia at an early age. Neuropsychologia 25:341-357.

Overman WH, Ormsby G, Mishkin M (1990) Picture recognition vs picture discrimination learning in monkeys with medial temporal removals. Exp Brain Res 79:18-24.

Parkinson JK, Murray EA, Mishkin M (1988) A selective mnemonic role of the hippocampus in monkeys: memory for location of objects. J Neurosci 8:4159-4167.

Rehbein L, Zola-Morgan S, Mahut H, Moss M (1980) Failure of sparing, or recovery, of recognition memory after early hippocampal resections in the rhesus macaque. Soc Neurosci Abstr 6:88.

Rodman HR, Skelly JP, Gross CG (1991) Stimulus selectivity and state dependence of activity in inferior temporal cortex in infant monkeys. Proc Natl Acad Sci USA 88:7572-7575.

Rossitch E, Oakes WJ (1989) Klüver-Bucy syndrome in a child with bilateral arachnoid cysts: report of a case. Neurosurgery 24:110-112.

Ruppenthal GC, Walker CG, Sackett GP (1991) Rearing infant monkcys (Macaca nemestrina) in pairs produces deficient social development compared with rearing in single cages. Am J Primatol 25: $103-113$.

Saunders RC, Aigner TG, Frank JA (1988) Magnetic resonance imaging of the rhesus monkey brain: reconstruction of experimental lesions. Soc Neurosci Abstr 18:456.

Saunders RC, Aigner TG, Frank JA (1990) Magnetic resonance imaging of the rhesus monkey brain: use for stereotactic neurosurgery. Exp Brain Res 81:443-446.

Squire LR, Zola-Morgan S (1991) The medial temporal lobe memory system. Science 253:1380-1386.

Stein DG, Rosen JJ, Graziadei J, Mishkin D, Brink JJ (1969) Central nervous system: recovery of function. Science 166:528-530.

Tonsgard JH, Harwicke N, Levine SC (1987) Klüver-Bucy syndrome in children. Pediatr Ncurol 3:162-165.

Tuynman FHB, Hekster REM, Pauwels EKJ (1974) Intracranial arachnoid cyst of the middle fossa demonstrated by positive $99 \mathrm{~m} \mathrm{Tc}$ brain scintigraphy. Neuroradiology 7:41-44.

Vargha-Khadem F, Isaacs EB, Watkins KE (1992) Medial temporallobe versus diencephalic amnesia in childhood. J Clin Exp Neuropsychol 14:371-372.

Webster MJ, Ungerleider LG, Bachevalier J (1990) Connections of inferior temporal areas TE and TEO with medial temporal-lobe structures in infant and adult monkeys. J Neurosci 11:1095-1116.

Webster MJ, Ungerleider LG, Bachevalier J (1991) Lesions of inferior temporal area TE in infant monkeys alter cortico-amygdalar projections. Neuroreport 2:769-772.

Wood FB, Brown IS, Felton RH (1989) Long-term follow-up of a childhood amncsic syndromc. Brain Cognit 10:76-86.

Zola-Morgan S, Squire LR (1985) Complementary approaches to the study of memory: human amnesia and animal models. In: Memory systems of the brain: animal and human cognitive processes (Weinberger NW, McGaugh JL, Lynch G, eds), pp 463-477. New York: Guilford.

Zola-Morgan S, Squire LR (1993) The neuroanatomy of memory. Annu Rev Neurosci 16:547-563.

Zola-Morgan S, Squire LR, Amaral DG (1989a) Lesions of the hippocampal formation but not lesions of the fornix or the mammillary nuclei produce long-lasting memory impairment in monkeys. J Neurosci 9:898-913.

Zola-Morgan S, Squire LR, Amaral DG, Suzuki WA (1989b) Lesions of perirhinal and para-hippocampal cortex that spare the amygdala and hippocampal formation produce severe memory impairment. J Neurosci 9:4355-4370. 